\title{
Focused Ethnography Through Thematic Networks: Defining Validity in Business Anthropology Research
}

\author{
Pedro Oliveira \\ CRIA/ISCTE
}

This article explores the question of validity of ethnographic findings in anthropology in general and business anthropology in particular. The main argument is that our ethnographic work is as methodologically valid as the production by human scientists of other disciplines. Unlike psychologists, however, anthropologists are yet to make a public claim to meaning (one outside the discipline) that renders our uses of methodology equally clear and open to public scrutiny. Business anthropology, hypothetically, could be a field marked by greater methodological accountability. Thematic networks could be the instrument used to start imagining forms of representing validity inside the discipline and as an instrument for future branding of business anthropology research.

\section{INTRODUCTION: VALIDITY AND BUSINESS ANTHROPOLOGY RESEARCH}

For Clifford Geertz, there is a literary genre missing in anthropology as a whole: this would be the equivalent of literary criticism or philosophical commentary brought to anthropology. As anthropologists, Geertz suggests, we constantly argue against each other's claims of meaning while the problem of how we build up and write up our anthropology works is yet to be the subject of a proper discussion (Geertz, 2004). Nothing could be more out of mind than taking on Geertz's suggestion and starting a discussion on literary criticism for a Business Anthropology issue.

Ann Jordan's seminal book (Jordan, 2003) has opened the way to a whole new field of inquiry in anthropology. This article is the first of a series of explorations on how participantobservation proceeds when an idea of anthropology of science, stemming from Latour along with others (Latour, 1993) meets business anthropology in thinking applied problems of observation in the field. To my knowledge, applied business anthropologists are not asked to be "literary" or to act as literary critics but to produce work that, in order to be persuasive, must rest upon an implicit claim of science, as opposed to literature, literary criticism, or any other form of artistic expression and art critic.

Different human sciences are unequally successful in managing a science image in the market. Up to the present day, despite signs of change, psychology, and motivational psychology in particular, has come to define the language of the corporate world more than the anthropology of 
consumer-research (Malefyt and Morais, 2010; Sunderland and Denny, 2007). The idea that consumers respond more to individualist motivations than contextual factors such as "culture" seems to limit how much anthropology can be brought to consumer-research. In this regard, Malefyt and Morais state that the job of an anthropologist working in business is not to engage in a claim of identity around the distinctive features of anthropology applied to consumer-research, but to take in the kind of psychological language played in the business world as one kind of native language, subject to anthropological analysis, while reaching for hybridized forms between psychology and anthropology (Malefyt and Morais, 2010, p.52). Simultaneously, within market research, a division seems to be occurring between market anthropologists and commercial ethnographers begging further questions on the identity of anthropology as a market research discipline (Malefyt, 2009, p.201). In the context of corporate anthropology, Suchman (2007) has talked of the importance of the anthropologist in branding their discipline effectively while incorporating the critical role that is dear to it. Such reflections crystallize in a first line of inquiry: how can we, as anthropologists, critically contribute to branding anthropology to a point that the discipline is not lost in identity struggles with psychology and/or commercial ethnography?

This article will proceed in tandem with Malefyt's and Morais' claim (2010) of looking for hybridized forms between psychology and anthropology that can serve anthropologists working in business anthropology. By assuming that form and content are aspects of one another, it suggests a slightly different way forward. In order for business anthropologists to gain ground in the market over business psychology and associated disciplines, without losing the distinctive qualities of anthropology as a whole, I suggest that adjustments can be made, or at least imagined, in the writing style of business anthropology research cases.

This article will proceed with three operations. Firstly, in form, this essay will serve as an experiment of a philosophical or literary commentary brought to business anthropology. Here, I slightly change the terms of the dialogue initiated by Geertz on the absence of literary or philosophical commentary in anthropology (Geertz, 2004) by narrowing down that commentary to a question of relation between literary structure and methodology. An argument is made that anthropology can brand itself further in the field of business by borrowing a leaf from psychology as far as methodology is concerned.

Secondly, I will explore the question of whether a particular analytical method imported from social psychology ("thematic networks") is a good candidate for addressing processes of analysis in business anthropology. Thirdly, I will be asking whether thematic networks can contribute to imagining different literary formats for writing up business anthropology articles. A suggestion is made that these new formats, or literary structures, in business anthropology texts and articles could include an abstract similar to articles in psychology. This abstract would contain information both on the process of research (e.g. number of fieldwork visits) as much as information on processes of data analysis.

Here, thematic networks can render matters more systematic by serving as an analytical tool that allows for comparison in processes of data analysis, across different case studies in business anthropology. I will provide examples to fundament this argument by re-interpreting case studies extracted from the work by Denny and Sunderland (2003) in terms of thematic networks. Last but not least, throughout the article, I will be thinking on the implications of bringing an idea of thematic networks to market anthropology in terms of the dichotomy emic versus etic (Pike, 1967), native theories versus scientific theories and what this may illustrate on the relation between psychology, anthropology and market research. 


\section{VALIDITY IN ANTHROPOLOGY AND BUSINESS ANTHROPOLOGY}

Images of scientific exactitude and presentational style can hardly be thought apart. Anthropologists are, and always have been, as exact in their science as in psychology or any other human science. Double-trained in psychology and anthropology, I feel safe to say that we know culture as well as any psychologist knows "personality" (or any other construct that is conventional in the structure of psychology as a discipline). Knowing is a vast idea that begs clarification. In reality, anthropologists do not know "culture" exactly in the way people outside the discipline tend to assume they do and psychologists do not know "personality" exactly in the way anthropologists and others often fear a psychologist does. In both cases, what both kinds of professionals have is slightly different means to learn about culture or personality in any given situation and render the exercise more systematic.

A second form of knowledge stems from the interaction between common sense and ideas like culture or personality. In a world ridden by double-hermeneutics (Giddens, 1987), science and common sense influence each other constantly. Knowing "things" like culture or personality is not immune to a double translation (or multiple translations even) of how such things are known inside a particular scientific community (psychology or anthropology) across two particular communities (cross-cultural psychology or psychological anthropology), between two or more scientific communities and between science and common sense as a whole. If common sense is a "cultural system," as Geertz has once suggested (Geertz, 1983), one must bear in mind that part of that culture is itself informed by ideas of culture made popular by anthropologists.

Anthropology, from my standpoint, is no less exact or sophisticated in methods of knowing and enquiry than any other human science. Anthropologists, methodology-wise, have always been just as modern. ${ }^{l}$ Our methods are different and so is our presentational style. Participantobservation per se is hard to argue as an experimental method. However there is no reason why a field of critical accountability around issues of the validity of the work we produce, similar to psychologists' production on issues of validity and reliability, cannot be brought to a discipline organized around an idea of participant-observation.

To claim a similar status of objectivity out there in the market, business anthropologists could make substantial gains by allowing for the creation of an internal field of discussion around the "validity" of ethnographic findings. The flipside of creating room for such a query is that for a while we would probably become more vulnerable to each other's eyes in terms of exposing how we draw conclusions analytically from ethnographic work. Also, such vulnerability may not always be compatible with the demands and language of the business world, or the competition played across different agencies. Whether a discussion on issues of validity in business anthropology, happening in the inter-cross of academia and practice is possible, only the community at large can decide.

How would we start by imagining a genre that focuses on validity inside business anthropology? Perhaps the answer lies in looking outside anthropology for what other disciplines assume "validity" to be. To take psychology as an example: the experimental categories of hard cognitive science (cognition, schema, etc) exist out there in nature no more than the categories of anthropologists (kinship, culture, etc). Studying humans in either case involves studying people who, in a particular socio-cultural context, are not thinking the world through the exact same categories of the scientist occupied with researching the categories of the people in question. Whether the organizing categories of a given scientist are "schema" and "cognition", on one side, and "kinship" or "culture" on the other, seems to me of lesser importance than acknowledging 
the fact that in both cases knowledge is obtained by a form of significant contrast between the categories of the researcher and the categories of the people studied.

Anthropologists, more concerned with setting in contrast the categories belonging to different groups of people, tend to address this contrast as the difference between an emic and etic perspective. Cross-cultural psychology, closer to anthropology in its investigations, sometimes alludes to a difference between psychology and "indigenous psychologies," in all ways resembling anthropologists' divisions between emic and etic. Whatever conflation happens between the two disciplines, the degree to which a given ethnographic study is effective in understanding the differences between external and internal views of the world, and setting them in contrast, is probably the way forward to start circumscribing validity in anthropology, and consequently in business anthropology.

Anthropologists, in the business world or elsewhere, in different forms, are concerned with differences between an emic and etic perspective that shed light on problems of the human condition. Applied anthropologists in general are as concerned with shedding light on general problems of the human condition as with feeding this knowledge of solution-oriented processes. The line between them, applied anthropology and anthropology, even for those who argue a line, is relatively fragile. The ethnographic path that leads one to conceive of something as a problem is the same path by which something comes to be classified as a solution from someone's point of view.

Replicability and validity are interrelated, but not the same. Ideally, replicability in anthropology would beg the question of whether two scientists facing a similar socio-cultural context would necessarily observe similar kinds of things. Here, the famous Morgan-Freeman controversy, with its obvious implications for business anthropology, would be a finished example of it (Tian, Lillis, and van Marrewijk, 2010). Validity in anthropology would approach the question in a slightly different manner. Validity in anthropology would beg the question of whether two different anthropologists facing a similar problem or socio-cultural context would draw similar conclusions on the basis of ethnographic data collected. Validity in business anthropology would probably extend the question and ask whether two different anthropologists occupied with the same problem would offer similar, or different, kinds of solutions to different clients.

To pursue such a noble quest, we would probably have to start by answering two basic questions:

1. How do we know that we are being successful in sieving emic and etic and providing an adequate account of both?

2. How are we coming to the conclusion that we have arrived at an emic view of the world that can either: contribute to shedding light on a particular problem of the human condition, and/or contribute to offering information that will feed into solution-seeking processes?

Above I have alluded to the fact that the contrast between the categories of the scientistpractitioner, psychologist or anthropologist, and the categories of the people studied in a given socio-cultural context, allows for knowledge of the people's worldview. For some, of a postmodern orientation, the exercise in question produces equal knowledge of both kinds: the scientist (and the group this scientist belongs to) and the people studied. It follows that any work of science, either an ethnography written by an anthropologist or an experimental piece in cognitive psychology is the setting in contrast of two different kinds of subject-object relation 
(that is, two different kinds of categories of meaning belonging to two different kinds of people) and no less exact in comparison.

The exactitude of an anthropologist should be judged on a criterion of meaning arising from notes taken and relations established between them on how much the material and subsequent analysis sheds light on the relation between two, or more, different kinds of subject-object relation involved in an ethnography study. In nature this is no different from the validity inferred in psychologists' statistical generalizations. Here, differences amount. While the validity of the psychologists' study is spelt by every article in a separate methodological section, anthropology is yet to conquer a similar form of persuasive writing that can be presented outside the discipline. Business anthropology could be a field allowing for greater persuasion in writing methodology while keeping intact the distinctive features of the discipline.

\section{METHODOLOGICAL ACCOUNTABILITY AND BUSINESS ANTHROPOLOGY}

At the beginning of this text, I warned the reader that I was about to proceed with a literary claim. By the end of the text I hope to persuade the reader that my literary claim is actually a scientific hypothesis. To turn literary criticism into a form of scientific reasoning that is useful for business anthropology, I have to dissect what I mean above by "in comparison."

By "in comparison" I mean that neither the logic of the anthropologist nor that of the experimental psychologist is more exact than the logic of the people studied, nor is the logic of either professional more exact that of than the rival discipline. To enhance communication with clients, and help brand business anthropology as effectively as other disciplines involved in business, probably the time has come for claims of meaning in applied business anthropology to be more carefully documented in how conclusions are drawn analytically from ethnographic data. A form of critical, methodological accountability could be created inside the field.

Form and content, in business probably more so than other fields, are aspects of one another. As a professional class, by and large, a psychologist's way of presenting knowledge as science is generally more persuasive in several ways. There is an alleged claim of greater distance between researcher and object in psychology, in comparison with anthropology, which, from an external point of view, bestows the work of psychologists with greater neutrality or objectivity.

As suggested above, in the writings of psychologists, an image of greater objectivity has also been built upon writing a separate section on methodology for each study. Ethnographic work produced by anthropologists, by contrast, is often permeated by an idea that participantobservation (the anthropological method par excellence) is found more or less everywhere in an article, study, or anthropological description. This tacit assumption may be at the root of dispensing with methodology in anthropology as an individual section as part of the standard structure of an anthropological article or study, in a form similar to psychology. Business anthropology could gain by introducing a methodology section into our articles and studies that would condense the analytical processes by which conclusions were drawn out of ethnographic data. Business anthropology is as good a field as any other, or probably a better one, to start staking a public claim to equal modernity of methods and sophistication of analysis. Let me elaborate.

To present itself externally as equally persuasive, business anthropology could try to extend Geertz's suggestion - or objection, as the case may be - and bring a form of critical accountability into the field, building upon questions of methodology. By and large, as a first step to it, this would consist of including a separate methodology section in our articles or studies that, 
similarly to those of psychologists, would illustrate the processes by which we have come to conclude things out of fieldwork material. Here, I mean something more (or something different) than listing how many fieldwork trips or ethnographic interviews were taken and in what circumstances. It is a well known fact that despite years of qualitative research, in anthropology and other fields, there is still a "regrettable lack of tools available for the analysis of qualitative material" allied with a "need for greater disclosure in qualitative analysis and for more sophisticated tools to facilitate such analyses" (Attride-Stirling, 2001, p.385).

By bringing greater critical accountability to the field through the exercise of borrowing from psychologists a form for writing methodology, I have in mind rendering clear to an audience outside the discipline how data analysis follows in business anthropology research. I also have in mind as a future goal comparing the steps by which an analysis of data occurs across cases of business anthropology written by different anthropologists. This would be done both with a view to rethinking applied ethnographic analysis in a systematic way and starting to unify business anthropology as a field, or as the case may be, making a point for a field that could grow out of methodological accountability.

My suggestion is far from exclusively academic. As a meta-investigation into how our knowledge is produced it can, in principle, provide business anthropologists with clearer insights into what anthropologists tend to see as kinds of solutions fitting particular kinds of clients. At this point, the counter-argument for the suggestion I am pushing forward is probably that I am conflating anthropology and ethnography in my line of thinking. I argue the exact opposite: it is precisely to avoid conflation between the two that I am separating ethnography and anthropology temporarily, only to bring them closer together by the end of this article.

Should these methodology sections be written in language that people with no formal training in anthropology, clients included, could potentially understand? The answer would have to be pursued case by case. In some cases, it could be worth the chance. Firstly, it could give clients an even clearer view of how their money is being put to use. Secondly, from a consumer-research point of view, exposing how conclusions were drawn analytically can be used to mirror processes by which consumers in general tend to arrive at particular kinds of conclusions. Thirdly, methodology sections written by psychologists, more so in quantitative studies, tend to make use of language that only an expert can understand. A non-expert, facing a quantitative psychology study, will be able to grasp that a "scientific" process presided over the collection and analysis of data but not fully able to follow all the analytical steps.

By writing methodology sections in language that a non-expert can understand, anthropologists could gain some ground over other disciplines involved in business. Fourthly, it could help consolidate the claim that ethnography is no less "exact" than any other human science involved in the field of business. Last but not least, expanding the exercise of writing methodology on the analytical side would involve nothing different from what we already do, but a slightly different way of presenting ourselves in writing. It could also contribute to undo equivocations that tend to happen when the clients "native theory" differs from the anthropological theory of the researcher in question. Cases like this have been reported in literature (Malefyt and Morais, 2010; Sunderland and Denny, 2003). Equivocations happen, for instance, when the native theory of the corporate world, sometimes excessively based on an idea of individual motivation, clashes with the "culture" view of the business anthropologist. In this article, equivocations will be alluded to by means of practical examples.

There are two main ways to read this text. The reader can choose to read this text as a literary claim covering a scientific hypothesis or a scientific hypothesis covering a literary claim. My 
persuasive abilities should be judged on my capacity of drawing the reader to the latter interpretation: that my literary claim is a scientific hypothesis that can push business anthropology further. In light of revision: my scientific hypothesis is that business anthropology could gain in including separate methodological sections in its articles, similar to the writings in business psychology or psychology studies in general. This could lead to the creation of a new literary genre within business anthropology, concerned with matters of methodological accountability.

Methodological accountability would try to answer the questions of validity in anthropology mentioned above. It would build upon the contents, language and methods of anthropologists, while borrowing a particular form of writing methodology from the writings of psychology. Academia and the business world separately cannot assist the birth of a new genre within anthropology. On this one, more so than usual, they would have to work together.

In pushing forward a literary claim by making use of the clearest language one can possibly come up with, different in form from the complexity in usage of language that we tend to associate to anthropological theory, I am asking readers to imagine whether a client could understand the matters discussed in this text, if not fully, to a great extent. Should I be successful in asking the trained anthropological reader in imagining themselves as a client reading this article, I will have won both my manifest and latent agendas.

My manifest agenda is that I am not here to present anything different from what business anthropologists or anthropologists in general already do. On the contrary, I am here to present a different suggestion of how to render systematic the way we communicate our findings to people with no training in anthropology, clients being an example, while doing so, branding the discipline even better. My latent agenda is that should I be successful in asking readers to imagine themselves as a client who could be reading this article for whatever unspecified reason, then I am doing more than writing anthropology in a "popular" style. I am de-complexifying language (as in taking the "complex" out of our language) with a deliberate purpose: laying complexity bare, while branding anthropology as a critical commodity "good for thinking" across different group and perspectives.

\section{FOCUSED ETHNOGRAPHY THROUGH THEMATIC NETWORKS}

The world of business moves quicker than academia and so should this article. The main suggestion herewith explored is that a new literary genre within anthropology could build upon analyses of business anthropology cases. Borrowing the term from Knoblauch (Knoblauch, 2005) I will be addressing this genre as "focused ethnography."

In borrowing the term I do not exactly hold in mind Knoblauch's idea of focused ethnography. Short-term field visits and greater time and data intensity, described by Knoblauch as constitutive parts of focused ethnography, are undoubtedly part of the definition. Substantial difference lies in the fact that it is the process of analysis in business ethnography that I am here concerned with, more than the analysis of the process. To think the process of analysis I literally borrow the term, but not the idea. Alternatively, while thinking focused ethnography, what I am holding in mind is the work of the social psychologist Attride-Stirling on "thematic networks" (Attride-Stirling, 2001).

"Thematic networks" is not a method of analysis per se but a pictorial representation of the different steps involved in the analysis of qualitative material. More of an analytical tool than a method of analysis per se, visual examples of pictorial representation on making sense of 
analytical data that could be easily conveyed to clients, or facilitate communication among business anthropologists, are found in Attride-Stirling's work (2001).

Pictorial representations of this kind could form separate sections of methodology in applied business anthropology articles or studies, not with a view to fully disclosing the method of analysis but with a view to illustrating the steps put in motion to arrive at a particular method of analysis in a given case. The ultimate aim of bringing thematic networks to applied business anthropology would be to illustrate how a particular analytical process unfolded over time through the series of short-term fieldwork visits and other techniques that constituted a process of research in business anthropology. By the end of this article, I shall provide the reader with some examples by re-reading a few business anthropology cases in the area of applied qualitative marketing. Beforehand, a remark is necessary: "The map is not the territory and the name is not the thing named" (Korzybski, in Bateson, 1979: 27).

As a tool of analysis, thematic networks are also designed to enhance communication between groups of people analyzing qualitative material and communicating about it with other groups. Focused ethnography through thematic networks, the label for the idea I am developing in this piece, is not the new literary genre per se but the idea that could lead to its constitution. At some level, dare I suggest, all applied business anthropologists practice a form of focused ethnography.

Unlike standard ethnographies written by anthropologists, applied business anthropologists do not have the luxury of a full year of fieldwork (or more) at their disposal while dissecting a group of people into several dimensions (e.g. gender, culture, kinship). In conventional anthropology conventional from the point of view of purposes and duration of fieldwork - dimensions such as kinship, culture, gender, etc, are generally given equal length or importance along the chapters of what constitutes an ethnography built over long-term fieldwork.

Beyond time constraints, in standard long-term anthropology and applied business anthropology, there is the question of what the anthropologist is trying to answer in the two kinds of research. The question a conventional anthropologist often departs from, at the beginning of fieldwork, is not necessarily the question the anthropologist ends with, as fieldwork comes to an end. In fact, one is expected to change the research question along the way and allow it to branch into a set of related questions intercrossing the different chapters of what we identify as ethnography.

Being funded by a university or educational funding body to pursue long-term fieldwork, or being paid by a client to draw conclusions through short-term fieldwork are obviously distinct in more levels than I can address. In comparison with work developed by business anthropologists in areas such as applied qualitative marketing, the question, or set of questions, the business ethnographer starts with should be the question(s) for which a sketch of an answer must come to the fore by the end of shorter fieldwork activities. Comparing the differences in literary structure between the two genres may provide us with a clearer view of differences. By two genres I have in mind, on the one hand, long-term fieldwork-based anthropology (where works produced by academic anthropologists are the example in mind) and on the other hand, short-term fieldwork business anthropology, as practiced in business anthropology and associated areas.

The question I am here to think aloud is whether these two genres, divided by the nature of the concerns of researchers of the two kinds and a fieldwork period generally shorter in the latter, unfold through slightly different logical reasoning.

In business anthropology work built over shorter and intensive periods of fieldwork, what seems to change along the process is the way in which different domains and sub-domains 
reorganize themselves right to the very end, to form a sketch of what the anthropologist was called upon to answer. This is intimately related, yet not exactly the same, as different domains gaining a life of their own and becoming a theme in themselves (e.g. culture or kinship) in longterm fieldwork in academic anthropology. In the former, research seems to start with a particular theme and hold onto this theme right to the very end; the theme seems to be defined by an intercross between the request made by the client and the anthropologist's critical view of this request; changes in the process concern the way different themes and sub-themes reorganize each other around the main theme which one started out with.

On the other hand, long-term fieldwork-based anthropology outside the business arena tends to start with a research question, or a set of interrelated questions. While trying to provide an account of how long-term fieldwork unfolded, themes like kinship or culture emerge along the process, not necessarily in relation to one main theme, but forming an independent structure of interrelated themes. By the end of it, in the latter form, there is often no "focused answer" required from the anthropologist, at least as an answer is understood in the business world. Rather, in the latter case, there is a series of answers and reflections leading to new questions, mirroring a thematic structure of interrelated themes given equal importance, with no centrifugal answer revolving around a central theme.

To use a meta-hypothesis: the latter genre could be seen as a tree of hypotheses branching out further and further as long-term fieldwork progresses, over one year or more. Business anthropology, on the other hand, seems better described by the image of a vortex where whatever is branching inside the structure, must do so in connection with a centre that is kept more or less constant right to the end of fieldwork. Taking inspiration from Attride-Stirling, I call this centre a global theme (2001, p.388). Persuasion is a main concern, inside and outside this article.

Should readers accept my warrant that these two genres tend to develop though different concerns that give rise to different thematic structures, than I can drag them to my suggestion of helping me to imagine how to start writing down issues of validity in business anthropology research. Should readers believe the dichotomy I just presented is an oversimplification, or that these two genres are always feeding one another and the differences between them are impossible to discriminate, or that validity is something that concerns the anthropologist alone for every single case, I assume I have lost them for good. In either case, time has come for examples.

\section{THEMATIC NETWOKS AND APPLIED QUALITATIVE MARKETING}

So far I have sketched relations between three main problems: the question of validity in anthropology and business anthropology; the question of methodological accountability; the differences in structure between anthropology works produced by long term fieldwork in "pure research" versus short-term, anthropologically-informed fieldwork. I have not resolved either of these problems. Rather, I have only started to sketch the relations between them. I am suggesting that thematic networks can help to reconfigure a relation between these three problems. It can help to address validity by instigating a shift of focus from a description of the process of research (e.g. number of fieldwork visits) to a description of the analysis of the process (e.g. for instance, how to organize data stemming from one fieldwork visit).

By allowing for comparison of different descriptions of process analysis across different case studies, it could instigate further discussion around methodological accountability. As a visual tool, it can serve as a way of illustrating the thought process of the analyst in making sense of 
ethnographic data. In tandem, it may be a suitable tool for any form of business anthropology that evolves through shorter periods of fieldwork and a circumscribed set of questions to start with. Further, as I hope to show, it can be used to think problems of equivocation or misunderstanding between clients and researchers by making visible clients' and researchers' differences in theory. Let me exemplify.

Every work asked of an anthropologist comes with its own set of problems. In the field of applied qualitative marketing, the work of Sunderland and Denny (2007) is an absolute breakthrough in rethinking across the idiosyncrasies of what is asked for in each particular case. For the purposes of this article, I will go back to a previous piece written by the authors on the intersection of psychology, anthropology and market research (Sunderland and Denny, 2003).

In a rather courageous piece, the authors explore cases of applied qualitative marketing that they were asked to contribute to, where relations with clients met with different degrees of success. More to the point, they dare to think aloud, in clear-minded anthropological style, why relations with clients met with different degrees of success, across distinct cases. In reinterpreting their claims, I hope to push my own claim forward.

In a study of pick-up trucks, Sunderland and Denny were asked to interview brand owners and competitive brand owners. The study involved multiple cities and demanded in-home interviews, driving demonstrations and week-or-more-long video diaries of owners' and vehicles' lives. Here, an equivocation was present from the beginning. As the client wanted the authors to answer questions such as "what kind of people drive a particular kind of vehicle," and match kinds of people with kinds of objects accordingly, the authors were trying to reframe the question in terms "what does it say in our world to drive a particular brand." Psychology versus culture shaped the equivocation from the onset. ${ }^{2}$ But what kind of psychology and what kind of culture are we bearing in mind in this equivocation?

While the client was thinking through a "folk," popular or indigenous psychological theory of human kinds (assuming that pick-up drivers have a psychosocial type that can be narrowed down to a constellation of psychological traits) the authors were thinking "human kinds" anthropologically, through a theory of culture. As Christina Toren brilliantly puts it, the "answer one gets to any question is a function of the terms in which the question is stated" (1999:11). Client and researchers were approaching the problem with different theories to start with: equivocations were bound to follow.

Another case described by the authors refers to a study of people who were early adopters of technology. The client was a telecommunications firm and a consultant psychologist was also involved in the case. Respondents were screened through an inclusion criterion pertaining to use of latest technology and a psychological questionnaire. They were required to submit selfproduced video presentations of themselves and the role of technology in their lives. Fewer than half of the people submitting videotapes were selected. Other procedures followed until ethnographic interviews and participant-observation were given room to play a part in the process. In this case, the authors mention that the particular difficulty was with the analysis phase, as the respondents, as a function of the screening they had been through, indeed shared a psychological profile. An etic, psychological "human kind", was not found in the field, as it were. It was the condition for building a field in the first place, obtained by psychological screening.

Researching the group, Sunderland and Denny uncovered broader socio-cultural aspects just as rich in detail (if not more) as insights gained through psychological screening. For example, in respondents' homes, books were done away with or put aside and totally replaced by technological gadgets; technology was used to separate business and personal realms (e.g. 
through the use of separate business and email accounts). In the final analysis of the case, the authors inform, the information considered relevant was the one that fitted with an initial idea of matching respondents with a profile of a psychological kind. Data on socio-cultural habits was discounted as less significant. Once more, they (as in the client on the one side, the ethnographer on the other) had departed from different theories leading to equivocation on either side. Clarifying the relation between theory and equivocation is required at this point.

In comparison with other human sciences, anthropology has always been a theoretically shy discipline (Gee and Warms, 2004). Circumscribing the notion of theory in the social sciences would involve an exhaustive literary review, way beyond the purposes of this article. I go rather for a simplified version of what theory stands for me extracted from work developed in anthropology and psychology. Theory is "something" that either blocks or releases possibilities of observation. As an anthropologist I do not believe (and I trust I am not alone on this one) in the inherent superiority of my theory over someone else's theory, whether that someone is a client, respondent, informant or a human scientist from a different tradition. Following Toren (2004) I believe that anthropology embodies a particular kind of theoretical validity (one that sets humans in relation to socio-cultural dimensions) just as psychology embodies a different kind of validity: one that tends to set humans, predominantly, towards psychological life. Matters conflate when an idea of psychological anthropology is brought to the table.

The world we live in, by and large, is more informed by ideas of psychological process than socio-cultural process, a fact well acknowledged by Sunderland and Denny in their article (2003). To test this hypothesis, switching on the television should do the trick. Take any spree killing case around the world. Talk of psychological profile on the spree killer will clearly outweigh talk of his socio-cultural life and the context they are part of. Television shows about FBI psychological profilers abound. A show trying to bring in a "cultural profiler" to solve murders would probably not live beyond the pilot. As we all know in anthropology, this does not mean that psychologists have got it more right in the sense that the knowledge they produce is closer to the way things really are. It means simply that, so far, they have managed to shape and influence common sense more than knowledge produced by anthropologists. It follows that common sense too has a theory that, as far as social life is concerned, is often a mix between different pieces of theory found across distinct human sciences. Between different theories, misunderstandings are likely to happen.

Where theories converge, so do the people who observe through them. Indeed a whole argument for the notion of "field," theorized via Bourdieu (1993) and others (e.g. Gupta and Ferguson, 1997) could be put forward as one of the global themes of future business anthropology. Brian Moeran's work (e.g. Moeran, 2005) stands as an important contribution to the exploration of the notion of field in business ethnography.

In what follows I will dissect three cases in applied qualitative marketing as examples of convergence and divergence of theory. Thematic networks will be brought to play as an instrument that can help identify areas of convergence and divergence when theories intercross and fields are formed.

\section{MARKETING VALIDITY IN ANTHROPOLOGY}

In 1961, in a classic study of social psychology, Serge Moscovici decided to research what the French middle-classes knew of Freudian psychoanalysis (Moscovici, 1961). He found that people with no formal training in psychoanalysis actually had a consistent image of Freud's 
theory going from an idea of "complex" to a schematic explanation of human suffering, inspired by Freudian terminology. Whether their folk schema actually corresponded to Freud's theory, in reality, is hard to determine as Freud's theory, up to date, keeps being discussed inside and outside psychology. The pertinent point is that at some level, people who were not psychoanalysts by training were beginning to think and express themselves in a similar language.

Any criterion of "exactitude" in understanding consumer behavior (or any kind of human behavior, for that matter) cannot rest on an uncritical query through the sciences that have managed to influence common sense the most. Rather, such a criterion must rest on the science (or sciences) that by showing how common sense is being influenced by a particular science, whether psychology, anthropology or other science, can give us a better view of how consumers think. Here, psychological anthropology is probably the strongest candidate. On the one hand, anthropologists are trained in taking a step back to divide emic and etic. Anthropology is, by nature, a meta-science, embodying a holistic tradition, trying to capture humanity in all dimensions, psychology one of these dimensions.

Due to their experience in sieving emic and etic, anthropologists are particularly apt to identify issues where consumers are thinking in ways similar to the theories of psychologists (emic), issues where consumers are not thinking in ways similar to the theories of psychologists (emic), while seeing how psychologists or anthropologists assume consumers are thinking in either case (etic). The point is that anthropologists strike a very high score in looking at problems through "native theories" set in contrast with "scientific theories." They are used of doing it with anthropology itself, part of the reason why the discipline may seem theoretically-averse to an outsider. We do not tend to breathe theory similarly to other human scientists. Yet we are no less exact about it.

A role open to future business anthropology research could be to take a step forward in rendering systematic what differences in "theory" are being played out there in the market, across the different groups we must work with, from psychologists, to respondents, to anthropologists themselves. Doing it through schematic images, case by case, unsophisticated as it may sound, is one way to it. Thematic networks could guide us into building pictorial representations with a view to illustrating the steps by which, along a given case in business anthropology research, we have come to draw conclusions upon the different theories played in the intercross of that case.

It would be unfair not to present one of Sunderland and Denny's successful cases, mentioned in the same article (2003). I will ask readers to bear one question in mind. What made this case successful (beyond the obvious high quality work of the researchers involved in the three cases here described)? Is it possible that client and anthropologists shared a similar theory right from the beginning, or have they come to a similar theory by the end of ethnographic work? Is there a possibility that by sharing a similar theory from the onset, it was easier for the client to understand the steps by which the authors were drawing conclusions along the process? I start with the authors' account: "One of the most successful cases we have undertaken succeeded because we were able to unwind and make visible the strands of both psychology and culture" (Sunderland and Denny, 2003, p. 194).

The case referred to by the authors concerns a study of drugs in the lives of children aged 913. In summarizing it, I fear I will not do justice to the complex work developed. The purpose of the research was to develop a drug prevention campaign strategy targeting the age group of children 9-13 (addressed as "Tweens," in the article mentioned). The authors start by stating that a "central tenet of our findings was that drugs are thoroughly implicated in American Tween's 
development of autonomous, bounded, private selves" (Sunderland and Denny, 203, p.195). A substantial part of the process, unlike the work with the pick-up drivers mentioned above, consisted of understanding that teenagers had their own kind classification of who uses a particular drug (e.g. "inhalants are for idiots").

Another breakthrough came with the understanding that from the teenagers' point of view, mastering a language of drugs was a synonym of maturity and psychological development. Finally, the authors made a case of how the language of drugs, as a metaphor, permeates American life in general (e.g. for instance, from a young age, teens heard messages about being "hyped" on sugar). Based on this triple source of information, the final advice to the agency centered round creating a campaign that would not target drug culture specifically in children's lives, but that would, in teenagers' eyes, challenge drug culture in American mainstream culture. The important element, feeding directly upon an idea of need of individuality and differentiation was to leave teenagers with the feeling that pursuing individuality and difference comes with opposition to American mainstream drug-culture at large, rather than alliance with it.

Substantial differences emerge in this case. Unlike the pick-up drivers' case study and the tech-savvy case study, the authors were given room to investigate what a native theory of human kinds is for the group of respondents in relation to the objects in question (e.g. "inhalants are for idiots"). Another way (perhaps a more radical way) of framing the same question: psychological business studies that draw almost exclusively on individual motivation as the explanatory frame of consumption, at some level, assume that respondents are thinking, behaving and using similar motivational concepts as the scientific psychologist analyzing the data. Where consumers are thinking like psychologists, that is, through a theory of individual motivation, psychologists are likely to get it right. Consumers are only human though, and therefore multi-layered. Where consumers are not thinking similarly to the theories of the psychology of motivation, psychology by itself is likely to miss the point and discard other forms of information which could well shed light on how consumers are thinking (and living).

Every anthropologist knows, by instinct even, that when campaigns are designed by shedding light on respondents' native theory of what drugs are about, there is a higher chance that when that campaign is out, teenagers and others will see their theory reflected in the campaign, rather than an external theory belonging to some experimental psychologist or academic anthropologist. In any case, effectiveness comes from producing campaigns within the frame of theory of the people studied. Good, applied, practical science does not proceed through higher claims of authority. It proceeds through higher claims of meaning by making evident the steps by which a native theory is better captured by a particular science. In evolving through claims of meaning, it may inadvertently serve to consolidate authority.

Above I have made a case that in comparison with standard ethnographies written by anthropologists over a year or more, all work in short-term fieldwork business anthropology is "focused." By focused I do not mean to imply greater discipline of thought involved (even if a case could be made for it) but a way of pursuing a particular problem where the initial research question is not endlessly reformulated, as often happens in long-term fieldwork processes/academic research. In the ethnographic cases written by business anthropologists, what seems to be constantly reformulated, in comparison with standard long-term fieldwork, is how the different domains and sub-domains reorganize themselves around the main theme or problem.

According to Attride-Stirling, thematic networks are thematic analyses that can be "usefully aided by and presented as thematic networks: web-like illustrations (networks) that summarize the main themes constituting a piece of text" (Attride-Stirling, 2001, p.386). In pursuing a 
pictorial representation of the organizing principle of data analysis, thematic networks evolve from the extraction of lower order premises (the so called "basic themes") to themes that encompass gradual levels of abstraction ("organizing themes") and meta-themes that encompass the inclusion of all material, the latter being called "global themes" (Attride-Stirling, 2001, p.388). The analytical steps involved in building a thematic network can be broken roughly into three stages: reduction or breakdown of a text, exploration of the text and integration of the exploration. In explaining the principles underlying these three stages, the author subdivides them into six stages, each formed by a few discrete analytical steps (Attride-Stirling, 2001, p.391). For the purposes of this article, I will not look into the six stages in detail, but trace the possible differences and similarities between fieldnote analysis and thematic networks:

\section{TABLE 1. \\ PICTORIAL REPRESENTATION OF A THEMATIC NETWORK VIA ATTRIDE-STIRLING}

\section{Basic Theme Basic Theme \\ Organizing Theme \\ Organizing Theme - GLOBAL THEME - Organizing Theme Organizing Theme \\ Basic Theme \\ Basic Theme}

If Attride-Stirling's method serves as a good candidate to answer Geertz's "how," a difference with anthropology needs to be established from the start. "Thematic networks" is a tool used when data collection is completely finished. It works mainly through induction. My experience of doing ethnography is one where as a function of new material collected for every field visit, there is a constant shift between induction and deduction happening from the outset. As new notes are coded and classified along the fieldwork process, domains sub-divide leading to new basic and organizing themes, shaping the meaning of the global theme in return, in a feedback loop.

Inspired by Attride-Stirling, I suggest that differently from psychology, a tool for business anthropology research would have to be based on an idea of "reversible thematic networks" insofar as the relation between global, organizing and basic themes can be reversed at any point, depending on how new ethnographic data feeds into the process. By identifying the points in the process where a thematic network has changed (for example, going from global theme to organizing theme or the other way around) we can potentially find points that are particularly significant in the ways different groups are thinking the problem in hand. For instance, let me try to represent the equivocation in the intercross of different theories found in the first study referred by Sunderland and Denny in a scheme below:

ORGANIZING THEME: Kind of people who drive a pick up-truck (popular psychology of human kinds) / CLIENTS' POINT OF VIEW

GLOBAL THEME (pick up-drivers as human kind)

ORGANIZING THEME: Cultural ideas on pick up drivers as human kind/RESEARCHER VIEWPOINT 
A first hypothesis for rethinking methodological accountability in business anthropology (that would need further consolidation by eliciting other business anthropology cases) is that when client and researchers have a different theory to form the organizing themes, progression from organizing themes to basic themes will prove particularly hard. Client and researcher will start by disagreeing on a major tenet and then evolve through distinct ways of observing the smallest things differently. The thematic network of a focused ethnography cannot be fully formed because different ways of observing through theory block the formation of basic themes seen as common between clients and researcher. Another way of representing the same problem would be:

\section{BASIC THEMES}

\section{ORGANIZING THEMES}

GLOBAL THEME (pick-up truck drivers)

Respondents' ideas on the kind of people who drive a pick-up truck

Psychologists' ideas on the kind of people who drive a pick truck

Anthropologists' ideas on Respondents, Client and Psychologists' ideas of pick up drivers as human kind (its intersection)

An exploration of the validity of a business anthropology case should focus equally on successful cases. Going back to the drugs campaign case:

\section{ORGANIZING THEMES}

\section{GLOBAL THEME (Campaign)}

BASIC THEMES---------------Individuality and differentiation

1. Teenagers" "human kinds" theory (e.g. "inhalants are for idiots")

2. Drugs and American culture (e.g. "being hyped on sugar")

3. Mastering drug-language as development

In comparison with the previous case, an obvious difference is that the clients' theory and the researchers' theory converged from the start around an organizing theme on individuality and differentiation. The chances that researcher and client would agree on the formation of basic themes (observing smaller things similarly) were therefore, higher from the beginning. Without wanting to stir the pot even further, I would dare to say that teenagers themselves had a theory of individuality and differentiation, which probably allows them to observe smaller things similarly to client and researcher.

Illustrating both cases in a pictorial way, through thematic networks, is not in any way meant to replace the brilliant and complex analysis of the material, effected by the authors on both accounts. It can lead, however, to a clearer view of how particular kinds of conclusions can, or cannot proceed along a business ethnographic research process in the intersection of the many theories played from the start. Validity would be a direct function of identifying the steps by which conclusions progress in the intersection of different theories, thought case by case.

\section{CONCLUSION}

While psychology keeps thriving in the West, through its greater persuasive ability to render its methods accountable and open to public scrutiny, anthropologists are still somehow shy of disclosing the analytical steps by which conclusions are drawn from ethnographic data. Business anthropology, as a new emerging sub-field, encapsulates all the potential to move anthropology 
forward in terms of methodological accountability. Thematic networks could serve as a pictorial tool that would allow us to start thinking methodological accountability case by case and in so doing, retrace the steps by which conclusions are made. Ideally, future discussions on the matter could serve as a starting point for imagining new ways of writing separate methodology sections in business anthropology literature, borrowing the form from psychologists' methodology sections. Business Anthropology, taking a leaf from psychologists' books, cannot (and should not) push away psychology in the process: on the contrary. Psychological anthropology can push business anthropology further to a point where both disciplines, psychology and anthropology, not to mention the world of business, can reach new destinations.

What implications would this new genre bring to business anthropology and anthropology as a whole? Several ideas come to mind. Firstly, the creation of a field of discussion around analytical issues of methodological accountability could help reframe business anthropology as a particular kind of critical commodity. By critical commodity I mean, literally, a commodity that remains critical of itself as a commodity. Business anthropologists do, more often than not, deal with commodities. Rendering even more explicit the processes by which business anthropologists arrive at analytical claims that capture commodities is a possible way forward.

Secondly, it could lend a new form to anthropology as a whole: a hybrid situated in the intercross of psychology, anthropology and the philosophy of science. Such a hybrid would co-exist with other forms found inside anthropology that are more literary and less driven by images of science, or at least, as the West tends to conceive science. These distinct forms would feed each other, rather than being mutually exclusive. Yet for this hybrid to ever come to life we would really have to move on from the idea that theory is ad hoc explanation or analysis. Theory is what allows for observation in the first place. Without theory, there can be no data and subsequently no possible analysis. Becoming a better observer, of gifts and commodities, within the frame of a business anthropology informed by an idea of science, would involve being precise in identifying differences in theory between researchers and clients that often give rise to equivocations.

Thematic networks can lend a precious hand in that regard. Going back to applied qualitative marketing as an example: if every "global" theme is formed by a difference between the clients" initial request and the anthropologist's critical interpretation of that request, to which the anthropologist returns to as a vortex, a form of complex critical life is already in motion from the start. To portray that critical life as an intersection of different theories, more than objectifying critical life itself as a commodity, can lend the path to being systematic in the processes by which a commodity is critically objectified. Lastly, there is the promise that comes with every new field as semi-explored territory.

Ideas like thematic networks and "controlled equivocation" (Viveiros de Castro, 2004) can push the field forward as instruments for enhancing better dialogue between the different groups involved in business and associated fields, inside and outside anthropology, while rendering different perspectives across groups equally valid. At this stage, the possibilities are endless. An anthropology really coming home from the tropics may just be one that extends the same alien gaze to commodities by which anthropologists of the non-West once learned to observe gifts. Like anthropology as whole, in its beginnings, the language of a business anthropology informed by ideas of the philosophy of science, may be uncomfortable to start with. Think of it as a commodity hiding a gift: the promise of new forms of anthropology waiting to be born, in business and beyond it. 


\section{ENDNOTES}

1. By saying we have always been just as modern, I fully concur with Latour that we have never been modern (1991). Another way of framing it is that, as anthropologists, we have neither ever been modern, nor have human scientists of other disciplines ever been more "modern" than anthropologists. For further thoughts on explorations of observation in business anthropology, please visit the author's blog in: http://appliedbusinessanthropology.blogspot.com/

2. In talking "equivocation" I bear a precise meaning of the word in mind extracted from Viveiros de Castro's thinking on perspectival anthropology and controlled equivocation (2002). Future writings around this idea will explore the idea of controlled equivocation further, as possible analytic tools for thinking design.

\section{REFERENCES}

Attride-Stirling, J. (2001).Thematic networks: an analytic tool for qualitative research. Qualitative Research, 1(3): 385-405.

Bateson, G. (1979). Mind and Nature: A Necessary Unity. Bantam, New York.

Bourdieu, P. (1977). Outline of a Theory of Practice, trans. Richard Nice (Cambridge: Cambridge University Press.

Bourdieu, P. (1993). The Field of Cultural Production. Columbia University Press.

Ferguson, J. and Gupta, A. (1997). Discipline and practice: "the field" as site, method, and location in anthropology in Ferguson and Gupta (eds). Anthropological Locations: Boundaries and Grounds of a Field Science, pp. 1-46. California Press.

Gee, R.J. and Warms, R.L. (1999) Anthropological Theory: an Introductory History. McGraw and Hill Humanities.

Geertz, C. (1975). The Interpretation of Cultures., New York: Basic Books.

Geertz, C. (1983). Common Sense as a Cultural System. In Local Knowledge. New York, Basic Books, p. 73-93.

Geertz, C. (2004) Interview at DSpace /Cambridge Archives:

http//www.dpace.cam.ac.uk/handle/1810/438. Retrieved in Sep. 2010.

Giddens, A. (1987). Social Theory and Modern Sociology. Standford University Press.

Jordan, A. (2003). Business Anthropology. Prospect Heights, Il: Waveland Press. 
Knoblauch, H. (2005). Focused Ethnography (Electronic Version) Forum: Qualitative Social Research, 6. Retrieved September 15, 2010, from http://www.qualitativeresearch.net/index.php/fqs/article/viewArticle/20/43

Latour, B. (1993). We Have Never Been Modern. New York: Harvester Wheatsheaf.

Malefyt, T. (2009). Understanding the Rise of Consumer Ethnography: Branding Technomethodologies in the New Economy. American Anthropologist, 111(2): 201-210.

Morais, R. and Malefyt, T., (2010). How Anthropologists can Succeed in Business: Mediating Multiple Worlds of Enquiry. International Journal of Business Anthropology. 1(1): 45-56.

Moeran, B. (2005). The Business of Ethnography: Strategic Exchanges, People and Organizations. Oxford: Berg.

Moscovici, S. (1961). La psychanalyse, son image, son public, University Presses of France.

Pike, Kenneth Lee (1967). Language in Relation to a Unified Theory of Structure of Human Behavior 2nd ed. The Hague: Mouton.

Suchman, L. (2007) Anthropology as "brand": Reflections on Corporate Anthropology (Electronic Version) Paper presented at the Colloquium on Interdisciplinarity and Society, Oxford University. Retrieved September 10, 2010, from

http://www.lancs.ac.uk/fass/sociology/papers/suchman-anthropology-as-brand.pdf

Sunderland, P. L. and Denny, R. M. (2003). Psychology vs. Anthropology: Where is Culture in Marketplace Ethnography? In Advertising Cultures. Timothy de Waal Malefyt and Brian Moeran, eds., Pp. 187-202. Oxford: Berg.

Sunderland, P. L. and Denny, R. M. (2007). Doing Anthropology in Consumer Research. Walnut Creek, CA: Left Coast Press.

Tian, R., Lillis, M., and van Marrewijk, A. (2010). General Business Anthropology. Miami, FL: North American Business Press.

Toren, C. (1999). Mind, Materiality and History. Explorations in Fijian Ethnography. London: Routledge.

Toren, C. (2004) Crença e historicidade (Belief and Historicity). In Fernando Gil, Pierre Livet and João Pina Cabral (eds) O Processo da Crença (The Process of Belief). Lisboa: Gravida, pp. 221-237.

Viveiros de Castro, E (2004) Perspectival Anthropology and the Method of Controlled Equivocation. Tipiti Journal of the Society for Anthropology of Lowland South America, 2(1): 3-22. 